\title{
Developing an Empathy Spectrum for Games
}

\author{
Adam Jerrett, Peter Howell \& Neil Dansey
}

\begin{abstract}
Games often encourage players to feel empathy for characters or scenarios by design. However, the term "empathy" is often misunderstood, and used in a variety of contexts as a substitute for feelings of sympathy, pity and compassion.
\end{abstract}

This article defines a distinction between these similar terms and uses their definitions to describe how players emotionally engage with a game. This helps define an empathy spectrum, ranging from pity to compassion, that can be used to subjectively classify different games.

To show the spectrum in use, the article discusses a variety of video games that can be placed at the spectrum's key points, before discussing how games might reach the spectrum's furthest point: compassion.

The research hopes that modelling these abstract psychological concepts on this spectrum can help game designers, players and scholars better understand the range of emotional responses present in games.

\section{Keywords}

Games, sustainability, empathy games, empathy, reflection

\section{Introduction}

Games and their ability to engender empathy or other values in their players has arisen as an interesting new topic in the field of game studies (Schrier, 2017). While this notion was mentioned in early seminal game studies works (see Salen \& Zimmerman, 2003; Schell, 
2014), values-driven design came to fruition with the Values at Play framework developed by Flanagan et al. (2005).

While values-driven design focuses on a number of "human" values (Schrier, 2017), this article focuses on one specific value: empathy. Empathy is sometimes described as an inherently human trait (Kunyk \& Olson, 2001), and is becoming increasingly important as a $21^{\text {st }}$ century skill, especially in intercultural and interdisciplinary workplaces (Riemer, 2007).

Games are particularly useful for $21^{\text {st }}$ century skill development (Alonso-Díaz, Yuste-Tosina, \& Mendo-Lázaro, 2019). As such, they are useful tools for exercising prosocial skills like empathy, with games sometimes being referred to as "empathy engines" (Sampat, 2017; Schrier \& Farber, 2017). Games put players in another's shoes and allows them to explore. This exploration allows players to experiment relatively free of consequence, and, in doing so, understand how similar actions may affect similar situations in reality (Gee, 2014).

As such, games can allow players to exercise empathy through play. However, there are varying degrees to which the empathy (often engendered by the game's story) can play a role in a game (Manney, 2008). A game's entire narrative can revolve around a core message that engenders empathy, like That Dragon, Cancer's exploration of a family member with cancer (Green, Larson, \& Green, 2016). Alternatively, players can simply feel empathy for characters or a situation at various points during play, like in Firewatch (Remo, Rodkin, Benson, \& Anderson, 2016) where players empathise with Henry and Delilah, the game's main characters, despite their many flaws.

This makes the term empathy game confusing. Not every game that makes players feel empathy (or other strong emotions) is an empathy game. Madigan and Dunlap (2019) argue that empathy is simply one aspect of a variety of emotional responses that can lead to actionable results, such as player reflection and kind actions. 
This article aims to tackle this confusion by examining the differences between pity, sympathy, empathy, and compassion to create an emotional spectrum. A variety of games are plotted on the spectrum to explore how each point on the spectrum is used in games. As a result, this article presents a model of emotional engagement in games for the purpose of game analysis.

\section{Defining Terms}

Dictionary definitions define pity as feelings of sympathy at other's troubles; sympathy as feelings of pity towards another's misfortune; empathy as understanding the feelings of another; and compassion as the sympathetic pity at other's misfortunes (Simpson \& Weiner, 1993). These definitions use similar terms interchangeably (e.g., sympathy discusses pity and vice versa) which creates confusion when trying to understand each concept. As such, these terms will be redefined for the sake of this article.

\section{Pity}

Pity, as with the other terms discussed here, initially had similar usage and definitions to sympathy and empathy. Early definitions focus on a feeling of care towards someone who has experienced misfortune, often with a focus on mercy or kindness (Wilmer, 1968).

The term held its sympathy-like usage until the early $19^{\text {th }}$ century, when hierarchical societies began to hold negative judgements of those being pitied (Gerdes, 2011). This negative connotation is noted by Wilmer (1968) when discussing the negative association of phrases like "I pity you". This has led to a contemporary usage wherein pity specifically deals with negative emotions like sorrow from a place of power when regarding the pitier's position to the pitied (Geller, 2006). Pitiers pity the downtrodden, but tread on them regardless (Wilmer, 1968). Pity is notably a directed emotional response, where one "[feels] sorry for" another (Geller, 2006; Gerdes, 2011). 
In this way, pity aligns with negative affects in affect theory. Using Tomkins' (2008) affects, the pitier may feel disgust, whereas the pitied may feel humiliation or shame. These affects being different supports the notion that pity is the most detached emotion of those being discussed.

\section{Sympathy}

Sympathy historically had similar connotations as empathy: both denoted "feeling with" someone (Gerdes, 2011). Early descriptions of sympathy, such as Hume (1888) denote the ability to sense the feelings of others. The act of sympathising in this context suggests a mirroring of emotions between the two parties (Soto-Rubio \& Sinclair, 2018).

Contemporary definitions include the same directed emotional response as pity, such as an expression of concern over another's circumstances (Clark, 2010). This approach requires more emotional engagement than pity, as the feeling is not specifically negative. This suggests that sympathy is the general response of "feeling for" another (Gerdes, 2011; SotoRubio \& Sinclair, 2018), which allows it to be placed between the negative pity and moreinvolved empathy.

As an affect, sympathy is largely positive due to its focus on concern for a target, and may align with Tomkins' (2008) positive "interest” affect, which requires engagement with another.

\section{Empathy}

Empathy is more complex than sympathy. Early use of the term stems from translations of the German term “einfühlung” (“in feeling”), especially in Freud's work (Depew, 2005). This usage promoted a complete understanding another's feelings by“'[putting] oneself in the shoes of another" (Soto-Rubio \& Sinclair, 2018). This is known as perspective-taking, and is often noted as an element of contemporary empathy definitions (Misch \& Peloquin, 2005) 
Contemporary neuroscience focuses on biological components of empathy such as the presence of mirror neurons that result in shared emotional responses between parties (Decety \& Moriguchi, 2007). However, the current article favours a psychological approach that understands empathy as mimicry that allows one to feel and understand the feelings of another (Batson et al., 1987). Empathy can be affected by the intensity of the emotion and the context in which both the empathiser and empathised find themselves. The personality of the empathiser and their relationship with the empathised also play a role (de Vignemont \& Singer, 2006).

These nuances (perspective-taking, context and intensity), along with "einfühlung" suggest that empathy's contemporary usage is to "feel with" rather than "feel for" (Gerdes, 2011; Soto-Rubio \& Sinclair, 2018).

Empathy can be further subdivided into three types of empathy: cognitive, reactive and parallel (Stephan \& Finlay, 1999).

Cognitive empathy is the understanding of another's feelings given their situation (Stephan \& Finlay, 1999). Like pity, cognitive empathy is detached: cognitive empathisers understand their target, but do not necessarily have an emotional response towards them. Psychopaths, for example, have high cognitive empathy: they understand the feelings of their targets, but have no emotional response towards them (Fallon, 2013).

Reactive and parallel empathy are both forms of emotional empathy (Stephan \& Finlay, 1999). Reactive empathy is a synonym for the earlier understanding of sympathy: emotions and felt by the empathiser, but they differ from those of the empathised. This still requires emotional engagement from the empathiser/sympathiser, but the empathiser's emotional response does not mirror the empathised. Parallel empathy, by contrast, relates to "feeling with" others, which has been discussed simply as empathy here. 
Like sympathy, empathy's requirement of engagement initially frames it as a positive affect (Tomkins, 2008). However, as one moves towards parallel empathy, this affect will change to match the target's emotional state, whether positive or negative. Parallel empathy can therefore awaken negative affects in empathisers like anger and distress, as situations that require empathy can result in intense emotional responses.

\section{Compassion}

Etymologically, compassion's Latin root, compassio, was used interchangeably with sympatheia in ancient Greek translations (Soto-Rubio \& Sinclair, 2018). This creates similar definition confusion as seen with previously-discussed terms.

Compassion's use as a verb - e.g. "Christ's compassion” (de Avila, 1852) - suggests additional action when compared to sympathy or empathy (Larkin, 2015). One is not simply attuned to another's emotional state, but actively does something to assist them (Soto-Rubio \& Sinclair, 2018).

These understandings of compassion (Larkin, 2015; Soto-Rubio \& Sinclair, 2018) are based in medicine, but altruism is similarly described in psychology by Ricard (2015) and Tisseron (2010) when discussing actioned empathy. Compassion, as a term, has seen adoption in game studies when discussing empathy-related action (see iThrive Games, 2018b; McDonald, 2018).

Compassion extends past empathy's emotional mirroring, and activates regions of the brain responsible for more serious emotions such as love (Singer \& Klimecki, 2014). Compassion is difficult to engage in due to this immense emotional requirement. Practitioners have to empathise and take action so strongly with another that it may personally or professionally impact them (Sinclair et al., 2016). Much medical research prioritises how practitioners can 
be compassionate without risking burnout or adverse mental health effects (Larkin, 2015;

Sinclair et al., 2016; Soto-Rubio \& Sinclair, 2018).

Compassion, as actioned empathy, is similar to parallel empathy when considering affect theory: the affect will be initially be dictated by the practitioner's empathetic response.

However, as compassion aims to help, the end result of compassionate action would likely be a positive affect like joy (Tomkins, 2008).

\section{Working Definitions}

As a result of these discussions, working definitions for each term are now presented. Each subsequent term relates to an increase in emotional engagement from an individual.

\section{Table 1: Working Definitions of "Empathy Spectrum” Emotions}

\begin{tabular}{|l|l|}
\hline Emotion & Working Definition \\
\hline Pity & Detached, negative emotional \\
responses to the plight of another
\end{tabular}




\section{The Empathy Spectrum}

This article visualises the increasing emotional engagement discussed as a spectrum (see Figure 1). The spectrum progresses through increasing levels of emotional engagement, moving from pity through to cognitive empathy, sympathy/reactive empathy, parallel empathy and finally compassion. Emotional responses of an individual move across the spectrum as they relate to the target of their emotions:

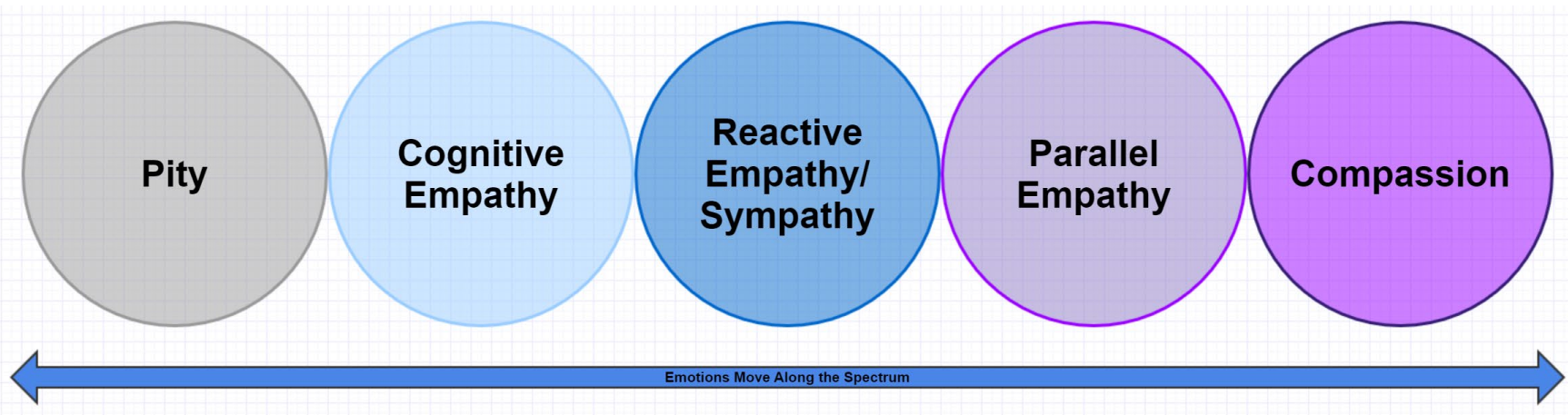

Figure 1: The Empathy Spectrum

\section{Research Questions}

Each point on the empathy spectrum defined in Figure 1 represents an increasing emotional engagement for an individual. This article seeks to understand how games encourage the spectrum's emotional responses in players during or after play. The research question of this article is therefore defined as:

How can games be classified in relation to their use of pity, sympathy, empathy and compassion on the empathy spectrum?

This presents the following sub-questions:

- How are pity, sympathy, empathy and compassion defined? (Answered by the previous section)

- How do these terms relate to games? 
- How can games be mapped onto the empathy spectrum to better understand how games utilise emotion?

\section{The Intersection of Games and the Empathy Spectrum}

Effective game narratives make their players feel emotions (Heussner, Finley, Hepler, \& Lemay, 2015). In an attempt to better understand and build these emotions into the player experience, various frameworks have been proposed that guide game designers in emphasising particular values, emotions and subjects. These include values-driven game design (Flanagan et al., 2005) and emotional game design (Isbister, 2016), among others. Because games have "invisible values" (Grace, 2010), the emotional responses of players may differ based on their personal contexts or throughout the duration of play. Understanding this full range of emotions during play remains difficult, but is of particular interest in educational contexts and affective computing (see Conati, Chabbal, \& Maclaren, 2003; Conati \& Zhou, 2002). Multiplayer environments present an additional level of complexity, as players are affected by other players as well as the game system (see Merkx, Truong, \& Neerincx, 2007; Rezaei \& Ghodsi, 2014).

Multiplayer emotions, especially in the context of this article's contributions regarding empathy in games, may be a useful topic for future research. However, this article limits its scope to emotions on the empathy spectrum in single-player games.

\section{Pity and Sympathy}

Pity and sympathy are emotions that require the least emotional engagement on the empathy spectrum. Because of this, these emotions are more easily utilised in other forms of new media, such as television or film (Hueth, 2019). As such, pity and sympathy in games tend to be emotional outcomes based on a game's narrative design: they are emotions felt for characters and scenarios. 
Games rarely acknowledge situations in which the player themselves could be the target of pity or sympathy, as this may make the player feel foolish. Rare examples of such design include areas in games that are explicitly patrolled by overly-high level enemies, or the intentionally-placed surprise traps in games like Dark Souls (Ito, 2011). These scenarios result in instant player death, implying how pitiful they are.

\section{Cognitive and Reactive Empathy}

Having a game make a player feel an emotion does not immediately make it an empathy game (Madigan \& Dunlap, 2019). This article discusses such games as games with empathy. Here, the use of empathy is an important narrative component of the player experience, but it is not central to the game's context or message. Empathy is a tool used by some narrative games in order to strengthen player identification with characters (Schrier \& Farber, 2017). This approach to empathy forms part of good narrative design (Heussner et al., 2015; McDonald, 2018), but ultimately relies more on understanding the target of the empathy than feeling with them.

To encourage cognitive empathy designers can include character-driven questlines that allow the player to learn about and consider how their actions affect non-player characters within the world (iThrive Games, 2018b).

Mechanically, designers can also encourage empathy by modelling a virtual space that needs to be maintained by a greater community. An example of this is Death Stranding (Kojima \& Sakamoto, 2019). In the game, players can build structures like bridges to assist them in traversing treacherous terrain. Once they link certain areas to the Chiral network (the game's version of the internet), the game's shared multiplayer features are enabled. This allows player-built structures to appear in other players' games and vice versa. This multiplayer structure encourages a positive sustainability loop, where players build and maintain structures for the collective good of all players that use that structure (Gerblick, 2019). 
Designers need to be particularly careful of the context in which they attempt to engender empathy, as these moments of empathy, when not implemented with nuance, may simply shock or traumatise players (McDonald, 2018).

For example, it is revealed in Silent Hill 3 that the monsters the player had been shooting were humans all along. This evokes emotions of disgust and shock in the player (Lankoski, 2007). While Lankoski categorises this as an empathetic response, this emotional response more closely matches McDonald's (2018) idea of trauma, and should be avoided.

Ultimately, the use of empathy as a narrative beat or mechanic in games needs to feel genuine, as noted by Belman and Flanagan (2010). If it feels forced, it can evoke the opposite response in players and make them feel resentful of the experience instead.

\section{Parallel Empathy}

Unlike games with empathy, this article defines an empathy game as a game where empathy is a core mechanic or central to the game's message. Empathy games encourage the player to adopt an empathetic posture (Belman \& Flanagan, 2010) which allows them to connect with the game's message and characters through parallel empathy. Many academic studies that focus on empathy in games target a feeling of parallel empathy in players.

Advances in augmented and virtual reality (VR) technologies allow for immersive interactive experiences (Milk, 2015). A Breathtaking Journey (Kors, Ferri, van der Spek, Ketel, \& Schouten, 2016) is a mixed-reality VR experience in which players assume the role of a refugee who is fleeing their country in the back of a mandarin truck.

The mixed-reality component of the experience places players on a motorised contraption that simulates the truck's movement. Players also wear a mask that contains a breath sensor (used during gameplay) and a scent diffuser to diffuse the scent of mandarins. A controlled shutter also drops objects on the player during the game (Kors et al., 2016). In this way, the 
entire context of A Breathtaking Journey encourages the player to empathise in parallel with their avatar.

REAL LIVES, a video game, allows players take on the persona of a character in a different country, and vicariously experience pivotal moments in their character's lives to encourage intercultural empathy. Events in the game are based on real world data from the character's location (Bachen, Hernández-Ramos, \& Raphael, 2012).

Finally, ORIENT is a pervasive game in which teams of players play as members of a spaceship crew and each have a specific role (navigator, verbal communicator and non-verbal communicator) (Lim et al., 2011). The players land on an alien planet, and must convince its inhabitants, the Sprytes, that their planet is in danger from an oncoming meteor. During the game, players learn about the Spryte culture and are encouraged to understand it in order to convince the Sprytes of this danger.

These empathy games differ from games with empathy because of how they immerse the player in the game narrative (Schrier \& Farber, 2017). A major design consideration for these games is the serious nature of the games' narratives. Because games are voluntary activities (Salen \& Zimmerman, 2003; Suits, 1978), some players may choose to avoid engaging with such experiences through personal preference, regardless of the benefits these games may have in encouraging reflection and compassion.

Despite this limitation, the above studies demonstrate a growing academic interest in empathy games. This is useful as it allows designers to empirically see the outcome of their empathybased user experiences.

\section{Compassion}

The use of empathy in games remains divisive. Muncy (2018) finds the expectation that games should engender empathy disingenuous. In their view, games and their use of empathy 
can only go so far, and cannot, in themselves, mandate prosocial action. Transforming empathy into action is "[the player's] job" (Muncy, 2018). To encourage this, some studies examine how gameplay encourages subsequent prosocial action.

Greitemeyer et al. (2010) had participants play either Lemmings (a "prosocial" game) or Tetris (a "neutral" game) to discern the effects of prosocial games on behaviour. After playing either Lemmings or Tetris, participants were exposed to media vignettes about popular media celebrities and asked how strongly they empathised with the celebrity's situation (Greitemeyer et al., 2010). Results showed that players who played Lemmings experienced less joy at the celebrity's misfortune and expressed more empathy towards hypothetical situations of people in need when compared to the Tetris group.

A similar study by Happ et al. (2013) had players play a fighting game, Mortal Kombat vs DC Universe. Players controlled either popular DC comics characters Superman or The Joker and fought against the character to which they were not assigned.

Prior to gameplay, players were assigned to read either an empathic or a neutral version of their character's backstory and motivation. The effects of controlling these characters was then measured through players observing images of people with neutral facial expressions. Joker players perceived the neutral faces as more hostile, especially those who had read the empathetic Joker backstory prior to gameplay. Players of both Superman and the Joker who read these empathetic backstories also felt that the violence in the game was less justified (Happ et al., 2013).

Danilovic (2019) notes, when examining Overwatch (Blizzard Entertainment, 2016), that the game is designed both narratively and mechanically to engender prosocial behaviour in players. One example of such design is the game's "endorsement" system, where players can "endorse" other players for playing well or being sportsmanlike after the match has ended 
(Blizzard Entertainment, 2016). This design decision has the potential to foster a more positive in-game community (Danilovic, 2019). The encouragement of compassion that is fostered may subsequently allow players to transfer compassionate behaviours into their real lives.

\section{The Empathy Spectrum for Games}

Based on the above discussion, Figure 2 augments the empathy spectrum by showcasing how games with empathy and empathy games utilise specific emotions on the spectrum. Placing games in the context of this empathy spectrum allows their relation to emotions on the spectrum to be examined.

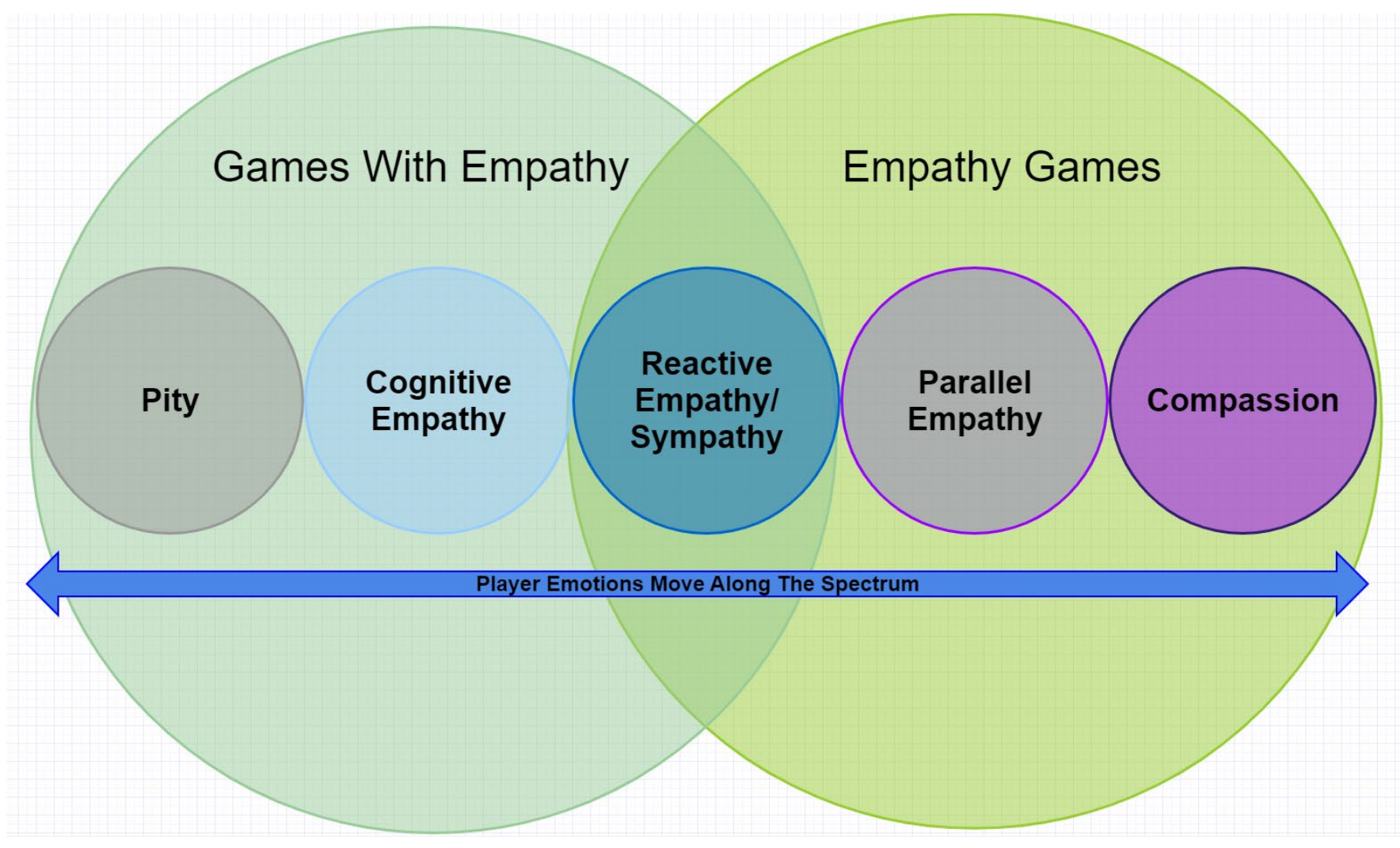

Figure 2: The Empathy Spectrum for Games

Figure 2 showcases the emotions targeted by both games with empathy and empathy games.

The empathy spectrum for games is primarily intended as an analytical tool to be applied to completed games, as it is difficult to definitively plot these games during design, when a 
game is changing rapidly. However, it can assist designers during the user testing phase of development to examine the success of the intended user experience. Using this model, players' emotional responses to games can be mapped onto the empathy spectrum to better define them as games with empathy, empathy games or a combination of these.

\section{Research Methodology}

Using the empathy spectrum as an analytical tool, the article examines and plots four games on the spectrum based on how they engage player emotions. Each game is discussed as a case study (Gerring, 2004).

Each chosen game attempts to highlight a specific range of emotions of the empathy spectrum. This was done to allow for clear elaboration of each emotion's phenomena within the model. Because any game can potentially map to a wide range of emotions on the spectrum, games with narrower emotional focus also provide useful points of comparison for how other games could be considered pity-focused games, sympathy-focused games or empathy games.

While empathy game lists do exist (see Games for Change, 2020; Holderman, 2014) and many articles discuss or study specific ones (see Belman \& Flanagan, 2010; Johnson, 2019), each source's definition of empathy game will guide what is eligible for study. This lack of consistency lead to a combination of convenience and purposive sampling being used in game selection (Pickard, 2013).

Based on the authors' available libraries of games, only single-player story-driven games were considered. Each title was then subjectively classified as affecting or non-affecting based on the emotional experiences noted in a research diary that was kept during the play of each game. This technique is suggested by Pickard (2013) for ethnographic study, and can be adapted to games because of their immersive qualities. 
Subsequent narrowing criteria included their level of critical acclaim (measured through an aggregate 75 or higher score on review aggregator Metacritic), as well as their mention in existing academic work. Finalist games were then ultimately judged on where the overall user experience might plot on the empathy spectrum itself. A subset of games in the selection process is shown below. Any red column excluded a game from further consideration.

Table 2: The Game Selection Process

\begin{tabular}{|c|c|c|c|c|}
\hline Game & Affecting? & $\begin{array}{l}\text { Metacritic } \\
\text { Score }\end{array}$ & $\begin{array}{l}\text { Academic } \\
\text { Work }\end{array}$ & $\begin{array}{l}\text { Place on the } \\
\text { Spectrum }\end{array}$ \\
\hline Papers, Please & No & & & \\
\hline Firewatch & Yes & 81 & (Kagen, 2018) & $\begin{array}{l}\text { Cognitive Empathy, } \\
\text { Sympathy }\end{array}$ \\
\hline $\begin{array}{l}\text { This War of } \\
\text { Mine }\end{array}$ & No & & & \\
\hline $\begin{array}{l}\text { The Beginner's } \\
\text { Guide }\end{array}$ & Yes & 76 & (Andrews, 2017) & Pity, Sympathy \\
\hline Rime & Yes & 78 & No & \\
\hline $\begin{array}{l}\text { That Dragon, } \\
\text { Cancer }\end{array}$ & Yes & 78 & (Schott, 2017) & Parallel Empathy \\
\hline Cibele & Yes & 71 & & \\
\hline $\begin{array}{l}\text { The Walking } \\
\text { Dead: Season } \\
\text { One }\end{array}$ & Yes & 89 & (Staaby, 2015) & $\begin{array}{l}\text { Cognitive Empathy, } \\
\text { Sympathy, Parallel } \\
\text { Empathy }\end{array}$ \\
\hline
\end{tabular}

Papers, Please and This War of Mine were both classified as "non-affecting" for this article because of their game systems' designs. While narratively poignant, they can mechanically encourage optimal play as opposed to empathetic play. Players may make in-game decisions 
that are best for their protagonists and the longevity of their play experience, regardless of the empathetic effect that has on other in-game characters.

The selection process resulted in The Beginner's Guide (Wreden, Breit, Flanagan, \& Higueras, 2015), Firewatch (Remo et al., 2016), The Walking Dead: Season One (Telltale Games, 2012) and That Dragon, Cancer (Green et al., 2016) being chosen for further analysis.

Because games are multimodal, they present complicated units for analysis using traditional document analysis methods (Carr, 2009; Consalvo \& Dutton, 2006). To avoid conflicting placement, given the subjective nature of game placement on the empathy spectrum, only one author examined all of the games discussed. Data collection was done using a hybrid approach: the previously-mentioned research diary was used, as well as a gameplay log as suggested by Consalvo and Dutton (2006). This resulted in a list of major gameplay events for each game and the author's emotional response to each. This data was then presented as a narratively framed case study.

The individual analyses of each game are not generalisable because of the subjective nature of both the data collection methods and narrative framing (Pickard, 2013). However, their framing and placement provide useful examples of how the empathy spectrum can be used as an analytical tool, as well as how games can use emotions on the spectrum to provide specific user experiences.

\section{Case Studies}

\section{The Beginner's Guide (Pity to Sympathy)}

In The Beginner's Guide (Wreden et al., 2015), players are guided by Davey Wreden, the game's designer, as a narrator, through the works of a game developer named Coda, a friend with whom Wreden has lost touch. To investigate Coda's disappearance, Wreden attempts to 
interpret the content of Coda's games through the lens of their relationship and what Wreden believes Coda's design intentions were. The player acts as a tourist in this exploration, being led through Coda's levels by Wreden. Players should quickly relate to Wreden's character in the game, as the feeling and exploration of friendship should be familiar to most players. The melancholy tone of this early exploration, where Wreden recounts a relationship with a friend who they have lost touch with, encourages players to feel sympathy for Wreden.

However, as the game progresses Coda begins to leave in-game messages for the player and Wreden to find. Coda, knowing that Wreden is exploring their games, criticises Wreden for the way they have presented Coda's personality and their work. Specifically, Coda notes that Wreden has edited Coda's games by intentionally placing literal lamp posts in them. This editing of Coda's work supports Wreden's explanation that Coda was an enigmatic person who imbued their games with hidden meaning.

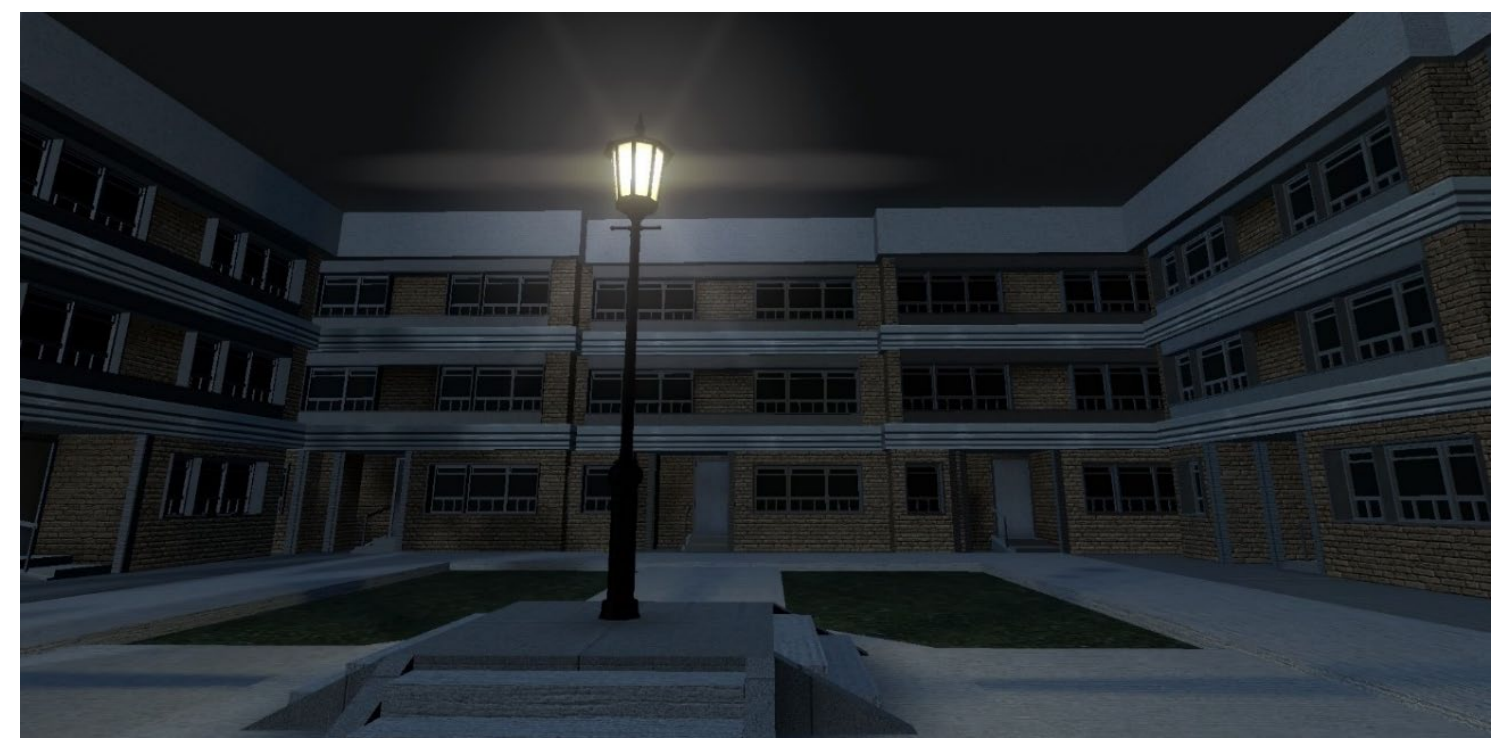

Figure 3: A "meaningful" lamp post in The Beginner's Guide

This paints the fictional Wreden as an unreliable narrator, who (in-game) admits that their creation of The Beginner's Guide serves as an apology to Coda for their wrongdoing. In the game's epilogue, Wreden muses about their need for validation as another reason for the 
creation of the game. Wreden's explanation of their selfish act allows players a window into their psyche.

This process of discovery for the player is where their initial sympathy for Wreden turns to pity. The player's sympathy shifts to Coda, a character who has been wronged by Wreden's selfish intentions.

The game is an interesting study on the notions of sympathy and pity for characters in games. The fictional Wreden talks directly to the player, which means that the pity and sympathy felt for them is felt directly by the player, as opposed to being channelled through the context of an avatar. This technique whereby a game engages directly with its player is used in various pervasive games, and could be a useful approach to engendering emotions more strongly in players.

\section{Firewatch (Cognitive to Reactive Empathy)}

Firewatch (Remo et al., 2016) follows Henry, a man who, following personal problems, escapes to Shoshone National Forest for a temporary job as a fire lookout. These personal problems are the first empathy-inducing moment of the game. Julia, Henry's wife, is suffering from early-onset dementia. Despite Henry's best efforts, he struggles to care for her. It is revealed in the game's opening sequence that Julia's parents are now taking care of her in their native Australia.

At this point, players may experience cognitive empathy. The game's opening sequence describes Henry's emotions and mental state regarding his scenario in detail to the player. As such, players should understand how Henry feels and why he is driven to take the fire lookout job after Julia's departure.

At Shoshone National Forest, where the game takes place, Henry "meets" Delilah, a fellow fire lookout responsible for another area of the park, through conversations over their radios. 
The banter between the two characters, who only ever converse through their radios, is arguably the game's core mechanic: Firewatch is about exploring the relationship between these two people who have never physically met.

As the game progresses, the relationship between Henry and Delilah deepens. Both have troubled pasts that inform many of the decisions that led to their jobs at Shoshone. The game's strong audio performances allows players a good understanding of both Henry and Delilah's mental states, which allows for cognitive empathy. As their relationship deepens, this may evolve into feeling reactive empathy for the characters and the scenarios in which they find themselves.

The game raises the stakes in this regard with a mystery plot that suggests Henry and Delilah are being watched by some outside force who is manipulating events at the park. This leads to cognitive dissonance for Henry. He is reliant on Delilah as his supervisor, but distrustful of her because of the strange events that are occurring. This tension deepens their relationship even further, which the player invests in over the course of the game. At this point the game moves from engendering cognitive empathy to engendering reactive empathy.

At the game's denouement, the mystery is solved. A third character, Ned, was watching both Henry and Delilah and manipulating events to scare them away from the park, where he has been living as a hermit for years. Ned has set fire to the park, which is rapidly spreading. Henry needs to rush to Delilah's lookout tower to be evacuated.

Over the course of the game, players emotionally invest in the Henry-Delilah relationship. There is an expectation that, at the game's climax, they would meet in order to gratify this investment. However, when Henry arrives at the tower, Delilah has left before him. They never meet. 
This subversive ending was controversial among players (Fyfe, 2016). This controversy proves, however, that Firewatch's ending ascends to having players feel parallel empathy: Both they and Henry are bitterly disappointed in Delilah's inability to commit to events in her life (in this case, meeting Henry) (Fyfe, 2016). This ending therefore reinforces the game's core message about the difficulties of "avoiding your responsibilities" (Fyfe, 2016).

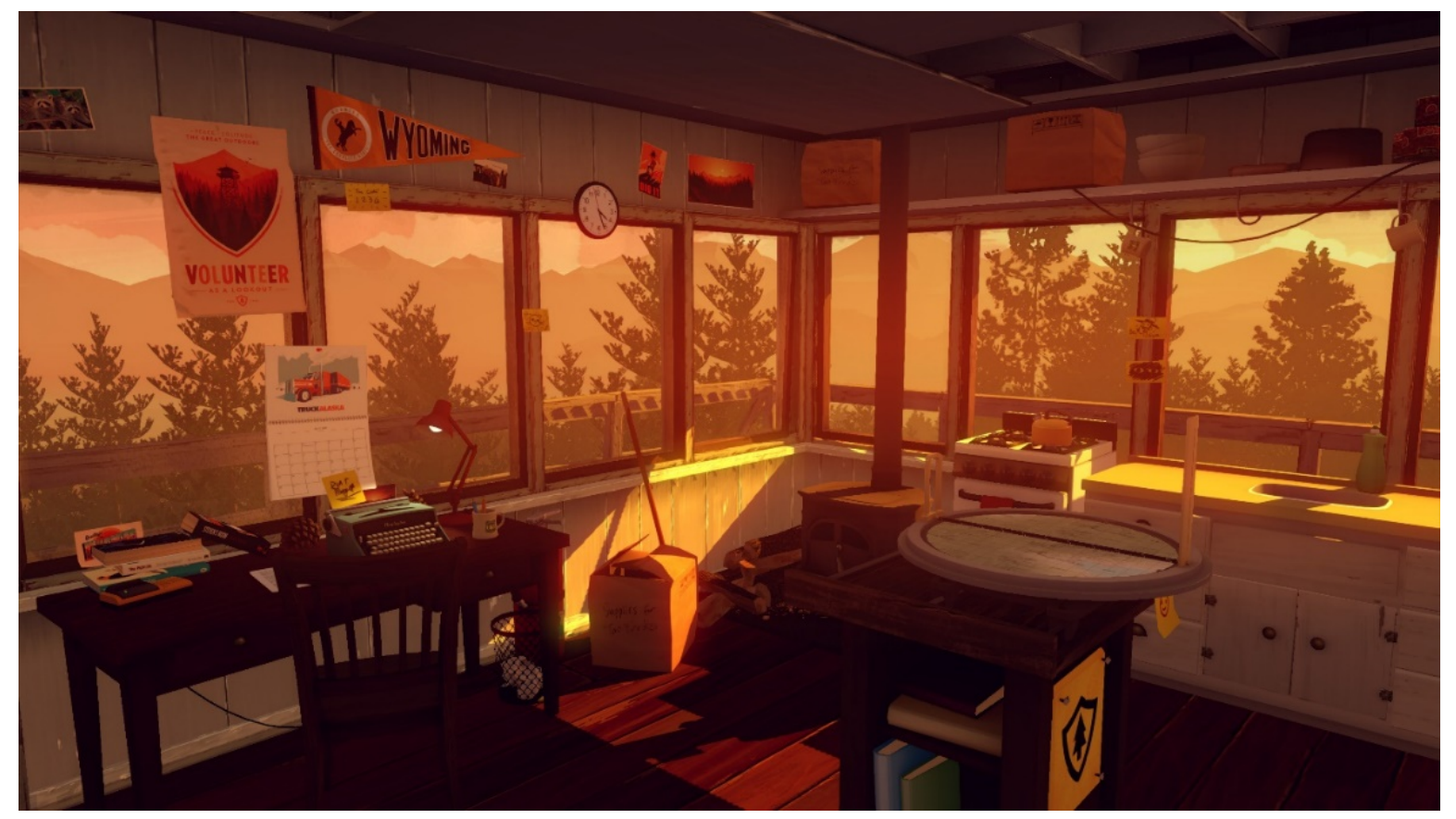

Figure 4: Delilah's empty lookout tower

\section{The Walking Dead Season 1 (Cognitive to Parallel Empathy)}

While The Walking Dead (Telltale Games, 2012) is set on Earth, ostensibly “in reality”, its zombie apocalypse setting frames it as fundamentally different to the grounded reality of Firewatch. Decisions made in The Walking Dead, due to the setting's dire circumstances, seem viable and logical in the game world, regardless of their potential consequences in the real world.

This positions the game as somewhere between a game with empathy and an empathy game. While its setting and context are not meant to engender empathy (there is no real-world analogue to a zombie apocalypse), the game's choice-based structure concerns itself almost 
entirely with ethics, empathy and an exploration of human values. This makes it useful (and used) as a games-based learning tool in some institutions (Schrier, 2019; Staaby, 2015).

As such, most decisions in The Walking Dead engender some type of empathy within the player. As the game begins, the empathy is likely mostly cognitive. Here, players understand the emotions of the various characters. However, due to the sparse early characterisation of these characters, players may make decisions unempathetically (Belman \& Flanagan, 2010) and base their decisions on what they feel is best for the collective group of characters.

The game soon introduces reactive empathy. Lee, the game's protagonist, finds and becomes the de facto guardian for a young girl named Clementine, who is found scared and alone in her family home. In their first meeting, players are likely to sympathise with Clementine, as she is an innocent, defenceless child.

Lee and Clementine soon meet up with a larger group of survivors and, over the course of the game, establish bonds with members of this group. At first, decisions made by the player that may affect the group engender cognitive and reactive empathy: they understand the horror of Lee's scenario, and sympathise with him and the larger party when complex moral dilemmas are presented. Over time, this reactive empathy evolves into parallel empathy, as players become more emotionally engaged in the experience and more "in tune" (McDonald, 2018) with Lee's emotional state.

This empathy reaches its climax at the end of the game. Lee is on the brink of death (and reanimation as a zombie) because of a zombie bite. At this point, players can decide to have Clementine shoot Lee or leave him to die and turn into a zombie. This is a moment of intense cognitive dissonance and parallel empathy for the player. Having Clementine kill Lee presents a similar moral dilemma to killing a family member. Players must directly wrestle 
with this quandary, mirroring Clementine's cognitive dissonance, before ultimately making a choice.

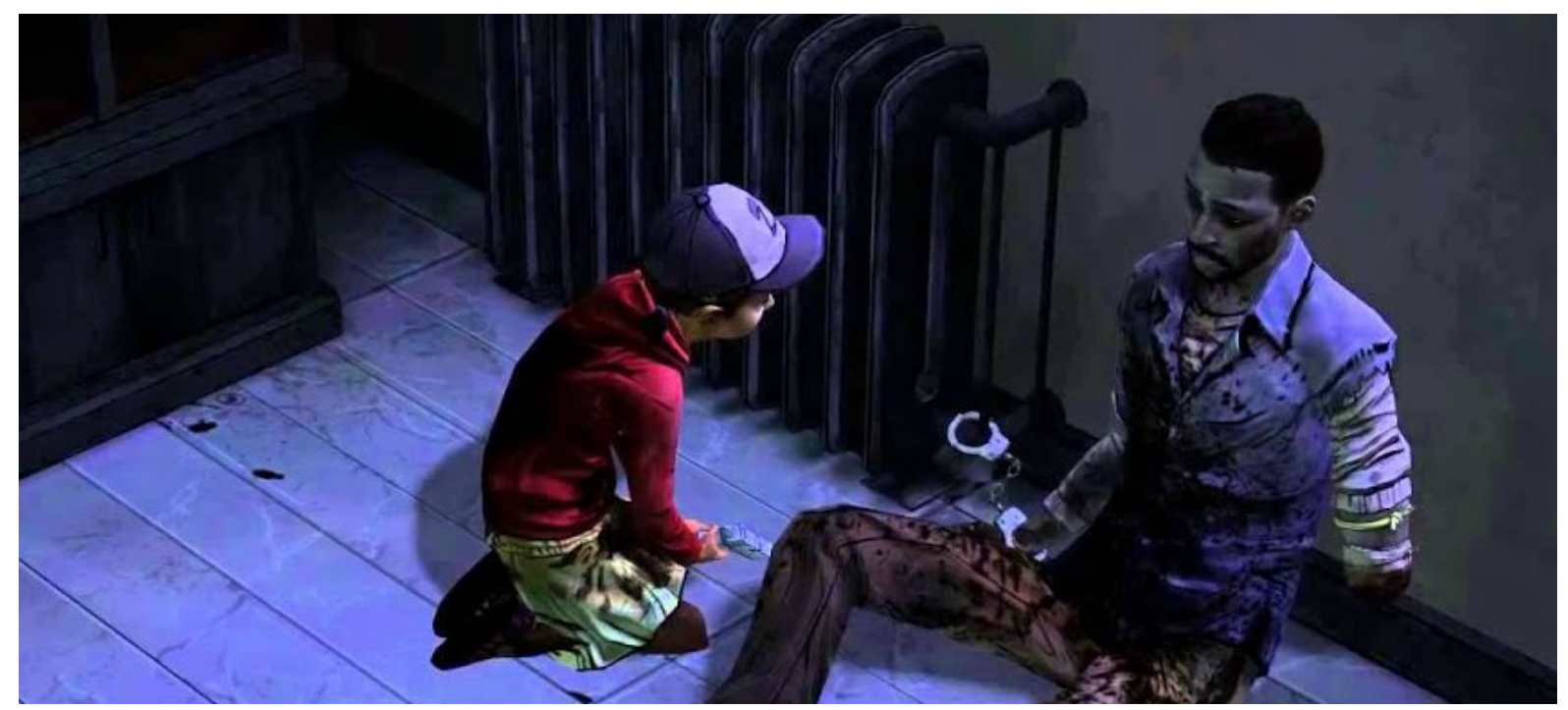

Figure 5: Lee's final moments with Clementine

The Walking Dead is also notable for its reaction to player choices. In the game, empathising or even being compassionate does not necessarily result in good outcomes. Some choices are equally $\mathrm{bad}$. This makes the game particularly valuable as an exploratory educational tool (Staaby, 2015).

\section{That Dragon Cancer (Reactive to Parallel Empathy)}

That Dragon, Cancer (Green et al., 2016) recounts the story of the Green family, as Ryan and Amy Green attempt to process the cancer diagnosis and eventual loss of their son, Joel.

Players often navigate the game as an invisible protagonist but sometimes control Ryan, Joel's father, whose perspective permeates much of the experience.

The degree to which players relate to each of the game's vignettes on the empathy spectrum is particularly personal to their own experience, given the game's subject matter. The game is acclaimed as particularly affecting and personal to play (see Harrer, 2017; Lawhead et al., 
2019; McDonald, 2018). As such, this analysis, more than the others discussed, incorporates the analyser's personal context.

The game quickly establishes a sympathetic tone. The game's first vignette is reasonably innocuous, introducing players to both Joel and Ryan. Near the end, there is model of a child in a hospital bed, foreshadowing Joel's struggles in hospital and eventual death. This, as Belman and Flanagan (2010) recommend, primes the player to empathise with the experience.

Parallel empathy is engendered during an early vignette where the player freely explores a hospital floor. The floor is decorated with cards, all of which contain messages that the game's early fans sent to the developers. The messages address deceased loved ones, as shown below. This direct addressing and the tone of the messages allows players to associate each letter with someone's personal experience of loss and reflect on their own experiences.
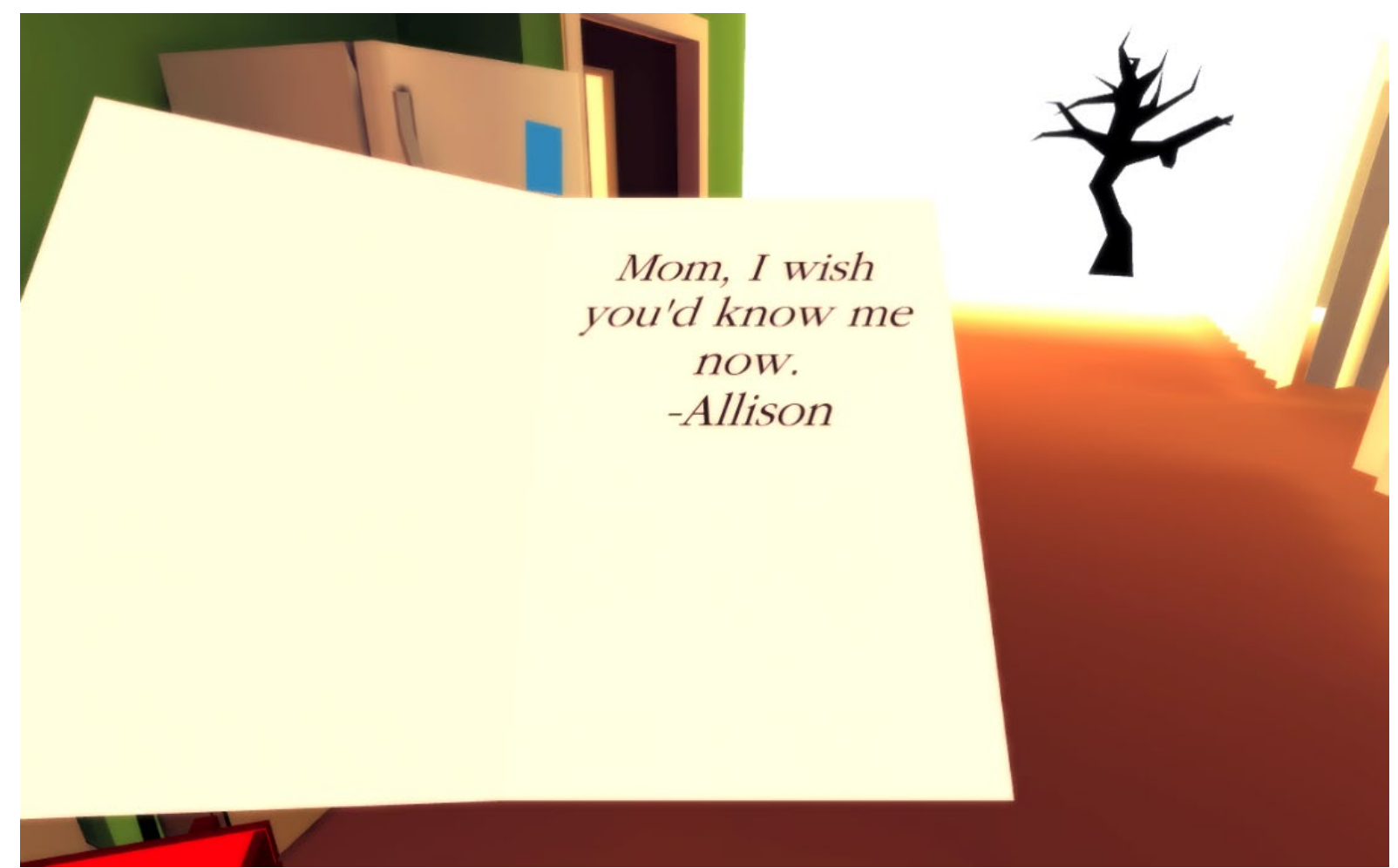
Oscillation between reactive and parallel empathy continues throughout the game. For example, players may feel either reactive or parallel empathy in the vignette where the Green family find out about Joel's cancer based on their own personal experience.

Empathy is also encouraged mechanically. In one vignette the player controls Ryan, who is underwater, and attempts to have him swim upwards to reach the surface. Because the water is a metaphor for Ryan's depression, attempts to have Ryan surface always fail. Instead, players must prompt Ryan to dive deeper into the water, Ryan's depression, to complete the sequence.

The tone of the game is melancholic as a result of its subject matter. This makes the game's ending in which Joel, presumably in heaven, is eating pancakes (his favourite meal) a moment of levity and relief. This vignette represents the Greens' vision of their son after his passing. The happiness and relief the player feels when experiencing this ending mirrors the emotions felt by the Greens when they consider Joel's life-after-death, presenting another example of parallel empathy.

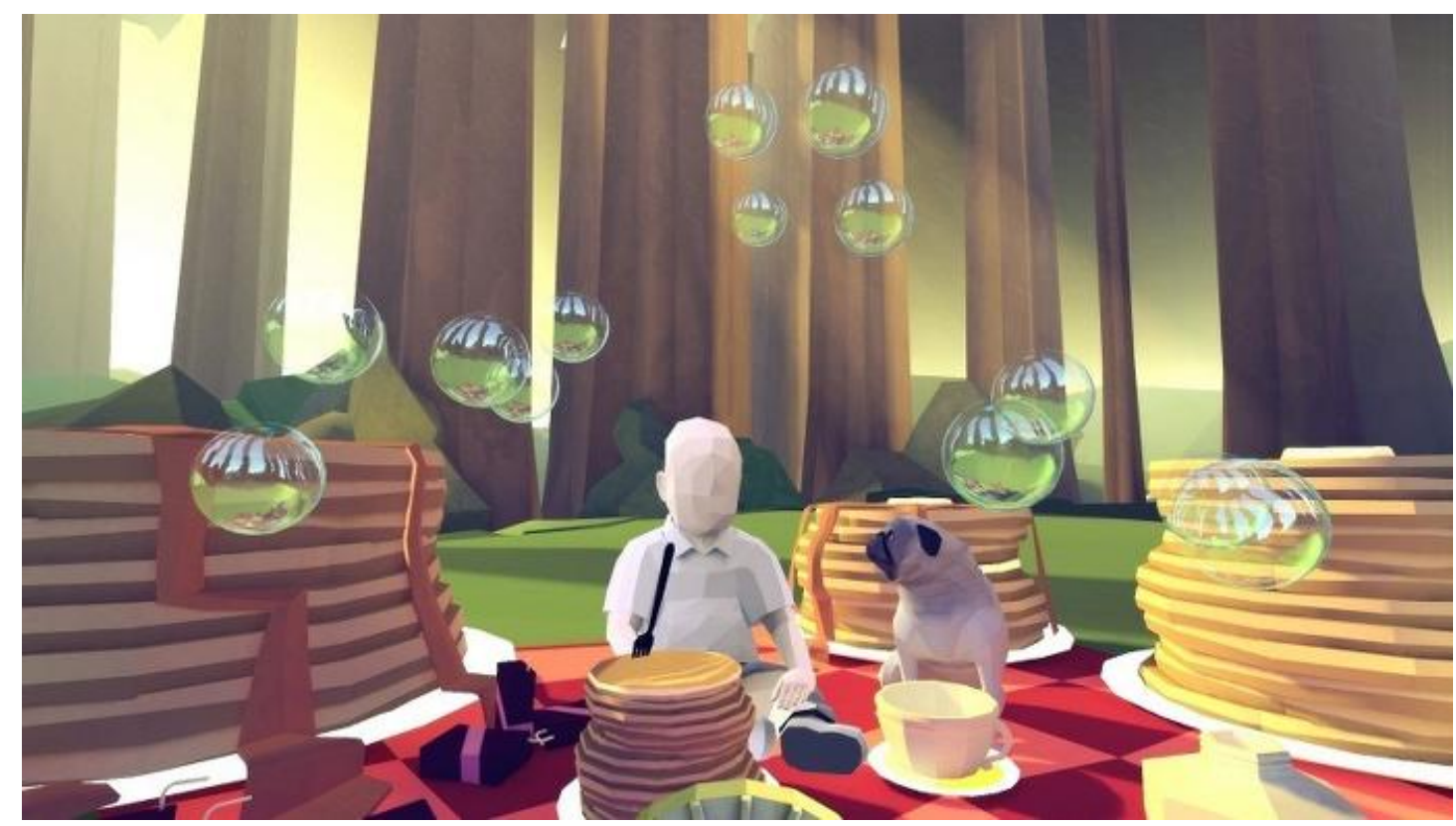

Figure 7: Joel in "heaven" 


\section{Discussion}

The above case studies showcase ways that the empathy spectrum for games can be used as an analytical tool. Each game highlighted a specific emotion or emotional range on the spectrum in order to provide clarity on how games can utilise those emotions, as well as how other games utilising similar emotional ranges could be analysed using the spectrum.

\section{Plotting the Case Studies on the Empathy Spectrum}

Figure 8 shows the plotting of the case study games on the empathy spectrum. As noted, this placement is specific to this article's analysis of the games, and may differ if another researcher analysed the same games. This may be a useful area of future research.

Another notable absence is how none of the games analysed reached the compassion emotion on the spectrum. 


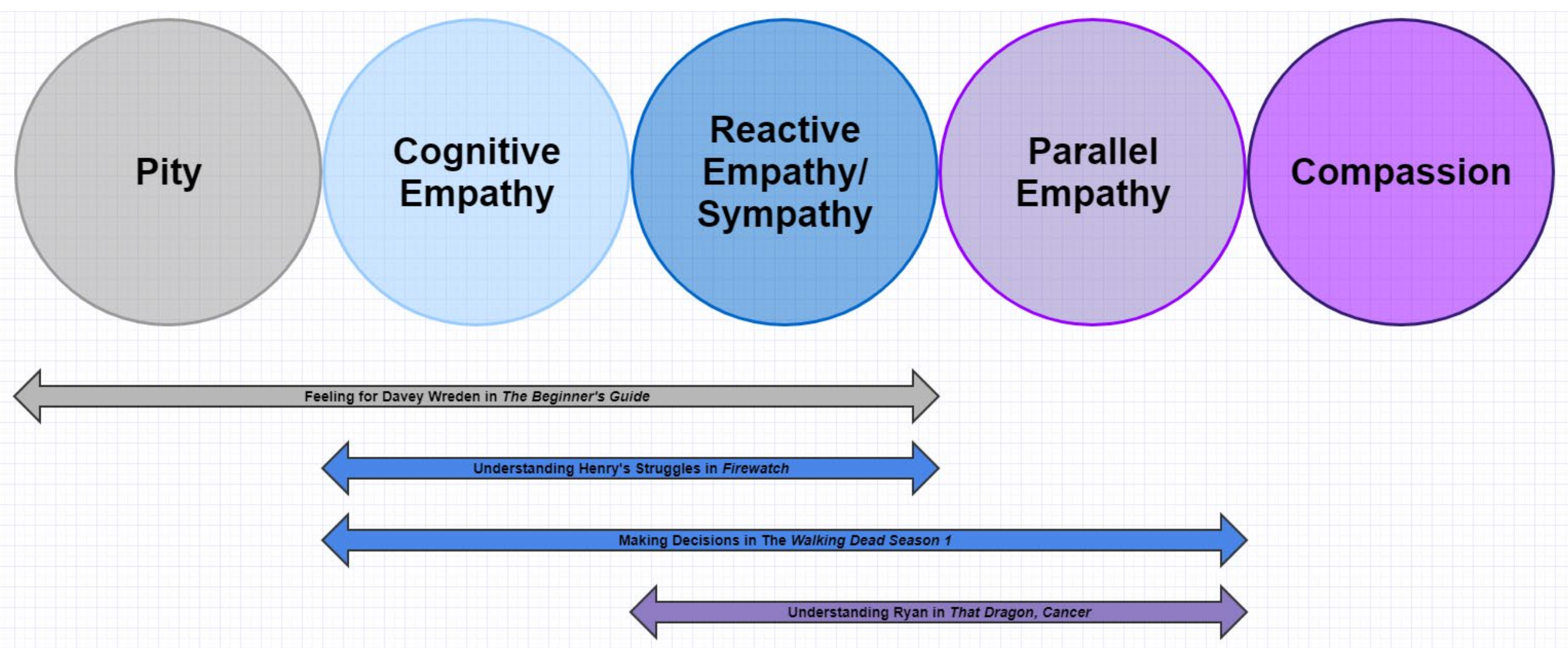

Figure 8: Plotting the Case Studies on the Empathy Spectrum 


\section{Towards Compassion}

Compassion was not examined as is difficult to address through game design when considered as an outcome (McDonald, 2018; Muncy, 2018). Games provide players with experiences but cannot control player actions after the fact. There have, however, been some games that incorporate compassion as a mechanic, like Kind Words (Scott, 2019).

Compassion can also emerge as an unintended outcome, like in SFZero (Dansey, 2013), but the intentional design of compassion remains difficult.

Compassion is thus a useful area of future research. Pervasive games are a useful genre to examine in this regard, as players often play as themselves, and directly engage in the game context. This can be seen in both Kind Words (Scott, 2019) and SFZero (Dansey, 2013), as well as other games like EVOKE (McGonigal, 2010). Live Action Roleplay (LARP), specifically "Nordic Larp", is another genre where game narratives encourage empathy or compassion as a game mechanic (Stenros \& Montola, 2010).

\section{Limitations of the Empathy Spectrum as an Analytical Tool for Games}

A shortcoming of the spectrum as an analytical tool is the subjectivity of game placement. While traits like pity can be examined by inferring the user experience based on the narrative revelations and characters' word choices, it is difficult to objectively classify a game as sympathy, empathy or compassion inducing using the model, as each player's experience may differ.

This may have consequences for reliability. Different analysers may plot the same game differently based on their experiences. This is a common problem in qualitative research that can be addressed using inter-rate reliability (Armstrong, Gosling, Weinman, \& Marteau, 1997). However, using inter-rate reliability with such analyses can eliminate the clear distinctions between the emotions and emotional ranges on the empathy spectrum used by a 
specific game. As such, the empathy spectrum likely provides more insight as an analytical tool when used by individuals, rather than groups.

Using inter-rate reliability, as well as the examining the outcomes of multiple empathy spectrum analyses on the same game could be a promising area for future research. Ways of quantifying emotions on the empathy spectrum in order to better categorise games could also be useful.

\section{Conclusion}

The research proposed an empathy spectrum of related emotions. Examining how these emotions are used in games, this article presents a tool, the empathy spectrum for games, that can be used to analyse complete games.

The empathy spectrum allows designers to examine existing games to understand how best to introduce empathetic moments and contexts into their own games. It also allows players to, as analysers, more fully engage with and understand the games they play.

To showcase this analytical tool, the research examined four games that were placed at different levels on the spectrum and explained why each game was placed there. Examining games at different levels of the spectrum provides designers and researchers with benchmarks to help them understand and plot their chosen games. This increased awareness of how empathy is used in games allows designers to more intentionally use empathy in their games, should they choose to.

While more research needs to be done on the notion of compassion within a gaming context, it is hoped that this article can inspire researchers and designers to more closely examine the power of empathy and compassion in games and similar interactive experiences. 


\section{References}

Alonso-Díaz, L., Yuste-Tosina, R., \& Mendo-Lázaro, S. (2019). Adults video gaming: Key competences for a globalised society. Computers \& Education, 141(1), 1-11.

Andrews, R. J. (2017). Metagames: Postmodern Narrative and Agency in the Video Games of Davey Wreden. University of Southern Mississippi, Aquila, MS.

Armstrong, D., Gosling, A., Weinman, J., \& Marteau, T. (1997). The Place of Inter-Rater Reliability in Qualitative Research: An Empirical Study. Sociology, 31(3), 597-606. SAGE Publications Ltd.

de Avila, T. (1852). The Interior Castle. (J. Dalton, Tran.). London, UK: T. Jones.

Bachen, C. M., Hernández-Ramos, P. F., \& Raphael, C. (2012). Simulating REAL LIVES: Promoting Global Empathy and Interest in Learning Through Simulation Games. Simulation \& Gaming, 43(4), 437-460.

Batson, C. D., Fultz, J., Schoenrade, P. A., Batson, C. D., Fultz, J., \& Schoenrade, P. A. (1987). Distress and empathy: Two qualitatively distinct vicarious emotions with different motivational consequences. Journal of Personality, 55(1), 19-39. WileyBlackwell.

Belman, J., \& Flanagan, M. (2010). Designing games to foster empathy. International Journal of Cognitive Technology, 15(1), 5-15.

Blizzard Entertainment. (2016). Overwatch. California: Blizzard Entertainment.

Carr, D. (2009). Textual Analysis, Digital Games, Zombies. Proceedings of the 2009 DiGRA International Conference: Breaking New Ground: Innovation in Games, Play, Practice and Theory (Vol. 5, pp. 1-8). Presented at the DiGRA 2009, London, UK: Digital Games Research Association. Retrieved from http://www.digra.org/wpcontent/uploads/digital-library/09287.241711.pdf 
Clark, A. J. (2010). Empathy and Sympathy: Therapeutic Distinctions in Counseling. Journal of Mental Health Counseling; Alexandria, 32(2), 95-101. Alexandria, United States, Alexandria: American Mental Health Counselors Association.

Conati, C., Chabbal, R., \& Maclaren, H. (2003). A Study on Using Biometric Sensors for Monitoring User Emotions in Educational Games. Workshop on Assessing and Adapting to User Attitudes and Affect: Why, When and How. Presented at the 3rd Workshop on Affective and Attitude User Modeling, Pittsburgh, PA: University of British Columbia.

Conati, C., \& Zhou, X. (2002). Modeling Students' Emotions from Cognitive Appraisal in Educational Games. In S. A. Cerri, G. Gouardères, \& F. Paraguaçu (Eds.), Intelligent Tutoring Systems, Lecture Notes in Computer Science (pp. 944-954). Presented at the Intelligent Tutoring Systems, Berlin, Heidelberg: Springer.

Consalvo, M., \& Dutton, N. (2006). Game analysis: Developing a methodological toolkit for the qualitative study of games. Game Studies, 6(1). Retrieved May 21, 2020, from http://gamestudies.org/06010601/articles/consalvo_dutton

Danilovic, S. (2019). Reimagining First-Person Shooter Games through Sociopoiesis. UnMediated: Journal of Politics and Communication, 1(2), 138-143.

Dansey, N. (2013). A grounded theory of emergent benefit in pervasive game experiences (Doctoral Thesis). University of Portsmouth, Portsmouth. Retrieved June 27, 2019, from https://researchportal.port.ac.uk/portal/files/4931948/NeilDanseyThesis.pdf

Decety, J., \& Moriguchi, Y. (2007). The empathic brain and its dysfunction in psychiatric populations: Implications for intervention across different clinical conditions. BioPsychoSocial Medicine, 1(1), 22.

Depew, D. (2005). Empathy, Psychology, and Aesthetics: Reflections on a Repair Concept. Poroi, 4(1), 99-107. 
Fallon, J. (2013). The Psychopath Inside: A Neuroscientist's Personal Journey into the Dark Side of the Brain. New York, NY: Penguin.

Flanagan, M., Howe, D. C., \& Nissenbaum, H. (2005). Values at Play: Design Tradeoffs in Socially-oriented Game Design. Proceedings of the SIGCHI Conference on Human Factors in Computing Systems, CHI ’05 (pp. 751-760). New York, NY: ACM.

Retrieved from http://doi.acm.org/10.1145/1054972.1055076

Fyfe, D. (2016, July 31). The End of Firewatch. Medium. Blog, . Retrieved November 20, 2019, from https://quarterly.camposanto.com/the-end-of-firewatch-8a7d334a9586 Games for Change. (2020). Games Archive. Games For Change. Non-Profit Organisation, . Retrieved May 21, 2020, from http://www.gamesforchange.org/games/

Gee, J. P. (2014). What Video Games Have to Teach Us About Learning and Literacy (Second Edition.). New York, NY: St. Martin's Griffin.

Geller, J. D. (2006). Pity, Suffering, and Psychotherapy. American Journal of Psychotherapy, 60(2), 187-205. Washington, US Minor Outlying Islands, Washington: American Psychiatric Association.

Gerblick, J. (2019). Kojima is most proud of Death Stranding's 'positive' shared-world multiplayer approach. Gamesradar. Retrieved November 15, 2019, from https://www.gamesradar.com/kojima-is-most-proud-of-death-strandings-positiveshared-world-multiplayer-approach/

Gerdes, K. E. (2011). Empathy, Sympathy, and Pity: 21st-Century Definitions and Implications for Practice and Research. Journal of Social Service Research, 37(3), $230-241$.

Gerring, J. (2004). What is a case study and what is it good for? American Political Science Review, 98(2), 341-354. 
Grace, L. (2010). Critical Gameplay_-Design Techniques and Case Studies. In K. Schrier \& D. Gibson (Eds.), Designing Games for Ethics: Models, Techniques and Frameworks (1st edition., pp. 253-274). United States of America: Idea Group Inc (IGI).

Green, R., Larson, J., \& Green, A. (2016). That Dragon, Cancer. United States of America: Numinous Games.

Greitemeyer, T., Osswald, S., \& Brauer, M. (2010). Playing prosocial video games increases empathy and decreases schadenfreude. Emotion, 10(6), 796-802.

Happ, C., Melzer, A., \& Steffgen, G. (2013). Superman vs. BAD Man? The Effects of Empathy and Game Character in Violent Video Games. Cyberpsychology, Behavior, and Social Networking, 16(10), 774-778.

Harrer, S. (2017). GGC 2017: Grief Based Game Design (by Dr. Sabine Harrer). GGC Gotland 2017. Gotland: Uppsala University. Retrieved July 31, 2019, from https://www.youtube.com/watch?v=ZmnMYtyA118

Heussner, T., Finley, T. K., Hepler, J. B., \& Lemay, A. (2015). The Game Narrative Toolbox. Burlington, MA: Focal Press.

Holderman, E. (2014, June 13). 13 Top Games That Teach Empathy. Common Sense Education. Retrieved May 21, 2020, from https://www.commonsense.org/education/articles/13-top-games-that-teach-empathy Hueth, A. C. (2019). Scriptwriting for Film, Television and New Media (1st ed.). New York, NY: Routledge.

Hume, D. (1888). A Treatise of Human Nature. Clarendon Press.

Isbister, K. (2016). How Games Move Us: Emotion by Design. Playful Thinking (1st edition.). Cambridge, MA: The MIT Press. 
iThrive Games. (2018a). Kindness In Games: IThrive Design Kit. iThrive Games. Retrieved December 6, 2019, from http://ithrivegames.org/wpcontent/uploads/2019/03/Kindness_DesignKit_3.12.18.pdf

iThrive Games. (2018b). Empathy In Games: IThrive Design Kit. iThrive Games. Retrieved December 6, 2019, from http://ithrivegames.org/wpcontent/uploads/2019/03/Empathy_DesignKit_3.12.18.pdf

Ito, J. (2011). Dark Souls. Souls. Tokyo, JP: FromSoftware.

Johnson, A. (2019). Using Empathy Games in the Social Sciences. Educause Review. Magazine, . Retrieved May 21, 2020, from https://er.educause.edu/articles/2019/11/using-empathy-games-in-the-social-sciences Kagen, M. (2018). Walking, Talking and Playing with Masculinities in Firewatch. Game Studies, 16.

Kojima, H., \& Sakamoto, A. (2019). Death Stranding. Japan: Kojima Productions.

Kors, M. J. L., Ferri, G., van der Spek, E. D., Ketel, C., \& Schouten, B. A. M. (2016). A Breathtaking Journey. On the Design of an Empathy-Arousing Mixed-Reality Game. Proceedings of the 2016 Annual Symposium on Computer-Human Interaction in Play, CHI PLAY '16 (pp. 91-104). Presented at the Annual Symposium on ComputerHuman Interaction in Play, New York, NY: ACM. Retrieved from http://doi.acm.org/10.1145/2967934.2968110

Kunyk, D., \& Olson, J. K. (2001). Clarification of conceptualizations of empathy. Journal of Advanced Nursing, 35(3), 317-325.

Lankoski, P. (2007). Goals, affects, and empathy in games. Proceedings of the Philosophy of Computer Games Conference, 2007 (pp. 1-10). Presented at the Philosophy of Computer Games, Modena: Philosophy of Computer Games. 
Larkin, P. J. (2015). Compassion: The Essence of Palliative and End-of-life Care. Oxford University Press.

Lawhead, N., Sui, J., Snow, P., Snow, K., Hsia, J. J., \& Freeman, N. (2019). Personal Experiences as Games. Independent Games Summit. San Francisco, CA: Game Developers Conference. Retrieved June 12, 2019, from https://www.gdcvault.com/play/1025675/Personal-Experiences-as

Lim, M. Y., Leichtenstern, K., Kriegel, M., Enz, S., Aylett, R., Vannini, N., Hall, L., et al. (2011). Technology-enhanced role-play for social and emotional learning context Intercultural empathy. Entertainment Computing, Entertainment Interfaces, 2(4), 223231.

Madigan, J., \& Dunlap, K. N. (2019). Empathy in Video Games. The Psychology of Video Games. USA. Retrieved May 20, 2020, from https://www.psychologyofgames.com/2019/07/podcast-50-empathy-in-video-games/ Manney, P. J. (2008). Empathy in the Time of Technology: How Storytelling is the Key to Empathy. Journal of Evolution \& Technology, 19(1), 51-61.

McDonald, H. (2018). Making Them Care: The Narrative Burden for Creating Empathy. GDC Narrative Summit 2018. San Francisco, CA: Game Developers Conference. Retrieved June 12, 2019, from https://www.gdcvault.com/play/1025424/MakingThem-Care-The-Narrative

McGonigal, J. (2010). Urgent Evoke: What Went Right, What Went Wrong: Lessons from Season 1 of EVOKE. Retrieved March 23, 2015, from http://blog.urgentevoke.net/2010/07/26/what-went-right-what-went-wrong-lessonsfrom-season-1-evoke1/

Merkx, P. A. B., Truong, K. P., \& Neerincx, M. A. (2007). Inducing and measuring emotion through a multiplayer first-person shooter computer game. Proceedings of the 
Computer Game Workshop (pp. 7-19). Presented at the Computer Game Workshop, Amsterdam, NL. Retrieved May 20, 2020, from

http://resolver.tudelft.n1/uuid:e5bf6a57-9079-4777-aaa4-e01614696678

Milk, C. (2015). How virtual reality can create the ultimate empathy machine. TED Talk.

Vancouver: TED. Retrieved November 15, 2019, from

https://www.ted.com/talks/chris_milk_how_virtual_reality_can_create_the_ultimate_ empathy_machine

Misch, D. A., \& Peloquin, S. M. (2005). Developing Empathy Through Confluent Education. Journal of Physical Therapy Education; St. Louis, 19(3), 41-51. St. Louis, United States, St. Louis: Journal of Physical Therapy Education.

Muncy, J. (2018). Stop Expecting Games to Build Empathy. Wired. Blog, . Retrieved November 12, 2019, from https://www.wired.com/story/games-and-empathy/

Pickard, A. J. (2013). Research methods in information (First Edition.). Chicago, IL: NealSchuman.

Remo, C., Rodkin, J., Benson, J., \& Anderson, N. (2016). Firewatch. San Francisco, CA: Campo Santo.

Rezaei, S., \& Ghodsi, S. S. (2014). Does value matters in playing online game? An empirical study among massively multiplayer online role-playing games (MMORPGs). Computers in Human Behavior, 35(1), 252-266.

Ricard, M. (2015). Altruism: The Power of Compassion to Change Yourself and the World (First North American Edition.). New York, NY: Little, Brown and Company.

Riemer, M. J. (2007). Communication Skills for the 21st Century Engineer. Global Journal of Engineering Education, 11(1), 89-101.

Salen, K., \& Zimmerman, E. (2003). Rules of play: Game design fundamentals. Cambridge, MA: MIT Press. 
Sampat, E. (2017). Empathy Engines: Design Games That Are Personal, Political, And Profound (2nd ed.). United States of America: CreateSpace Independent Publishing Platform. Retrieved June 12, 2019, from https://elizabethsampat.itch.io/empathyengines

Schell, J. (2014). The Art of Game Design: A Book of Lenses (Second Edition.). Boca Raton, FL: CRC Press.

Schott, G. R. (2017). That Dragon, Cancer: Contemplating life and death in a medium that has frequently trivialized both. Digital Games Research Association Conference (DiGRA) (Vol. 14, pp. 1-10). Presented at the Digital Games Research Association Conference (DiGRA), Digital Games Research Association. Retrieved May 21, 2020, from https://researchcommons.waikato.ac.nz/handle/10289/11325

Schrier, K. (2017). Confronting Games and Ethics: Challenging Students to Be Critical Designers. GDC Education Summit. San Francisco, CA. Retrieved May 21, 2019, from https://www.gdcvault.com/play/1024214/Confronting-Games-and-EthicsChallenging

Schrier, K. (2019). Designing Ourselves: Identity, Bias, Empathy and Game Design (pp. 149). San Francisco, CA: Center of Technology and Society. Retrieved June 24, 2019, from https://www.adl.org/media/13011/download

Schrier, K., \& Farber, M. (2017). The Limits and Strengths of Digital Games as Empathy Machines (Working Paper No. 5). MGIEP Working Paper (pp. 1-35). New Delhi: Mahatma Gandhi Institute of Education. Retrieved June 12, 2019, from https://unesdoc.unesco.org/ark:/48223/pf0000261993

Scott, Z. (2019). Kind Words. Boston, MA: PopCannibal.

Simpson, J. A., \& Weiner, E. S. C. (Eds.). (1993). Oxford English Dictionary (Second Edition.). Oxford, NY: Oxford University Press. 
Sinclair, S., Norris, J. M., McConnell, S. J., Chochinov, H. M., Hack, T. F., Hagen, N. A., McClement, S., et al. (2016). Compassion: A scoping review of the healthcare literature. BMC Palliative Care, 15(1), 6.

Singer, T., \& Klimecki, O. M. (2014). Empathy and compassion. Current Biology, 24(18), R875-R878.

Soto-Rubio, A., \& Sinclair, S. (2018). In Defense of Sympathy, in Consideration of Empathy, and in Praise of Compassion: A History of the Present. Journal of Pain and Symptom Management, 55(5), 1428-1434.

Staaby, T. (2015). Zombie-based critical learning - Teaching moral philosophy with The Walking Dead. Well Played: A Journal on Video Games, Value and Meaning, 4(2), $76-91$

Stenros, J., \& Montola, M. (Eds.). (2010). Nordic Larp. Finland: Fëa Livia.

Stephan, W. G., \& Finlay, K. (1999). The Role of Empathy in Improving Intergroup Relations. Journal of Social Issues, 55(4), 729-743.

Suits, B. (1978). The Grasshopper: Games, Life, and Utopia (First Edition.). Buffalo, NY: University of Toronto Press.

Telltale Games. (2012). The Walking Dead: Season One. The Walking Dead. San Rafael, California: Telltale Games.

Tisseron, S. (2010). L'empathie au coeur du jeu social (First Edition.). France: Albin Michel. Tomkins, S. S. (2008). Affect Imagery Consciousness: The Complete Edition (1st ed.). New York, NY: Springer.

de Vignemont, F., \& Singer, T. (2006). The empathic brain: How, when and why? Trends in Cognitive Sciences, 10(10), 435-441.

Wilmer, H. A. (1968). The doctor-patient relationship and the issues of pity, sympathy and empathy. British Journal of Medical Psychology, 41(3), 243-248. 
Wreden, D., Breit, M., Flanagan, R., \& Higueras, J. (2015). The Beginner's Guide. Austin, TX: Everything Unlimited Ltd. 